\title{
Street-Level Bureaucrats and Intersectional Policy Logic: a Case Study of LGBTQ Policy and Implementation Barriers
}

\author{
Amy Castro Baker ${ }^{1} \cdot$ Amy Hillier $^{1}$ (1) $\cdot$ Monique Perry $^{2}$ \\ Published online: 24 July 2020 \\ (C) Springer Nature Switzerland AG 2020
}

\begin{abstract}
Without clear federal mandates protecting the rights of transgender and gender nonconforming people, local governments are drafting their own legislation that either protects or limits these populations' rights. This leaves street-level bureaucrats situated in between competing auspices, conflicting mandates, and a constrained sense of selfdetermination when they are tasked with applying emerging legislation in a policy gray area. This paper considers the policy logic of an intersectional approach to LGBTQ policy, as well as the implementation barriers street-level bureaucrats may face when operationalizing LGBTQ policy in a politically complex environment. First, we use a piece of local legislation designed by transgender and LGB youth as an implementation case study focused on policy logic and policy triggers. Second, we employ thematic analysis for analyzing open-ended responses to 281 surveys completed by teachers and other school staff after training around implementation of a new district-wide policy anchored in an intersectional approach. Beyond normative, protracted implementation timelines, even when front-line workers were in full support of LGBTQ rights, tension still surfaces around the internalization of bureaucracy, fear of disciplinary sanctions, a perception of competing rights, and ambivalence with mediating between personal, familial, and youth agency. Even when using equity-focused policy approaches, stakeholders can expect to encounter implementation barriers with street-level bureaucrats (SLBs) while trying to influence higher orders of government through local advocacy and action. Altering the discourse on gender identity remains difficult in the current political environment surrounding LGBTQ rights.
\end{abstract}

Keywords Internalization of bureaucracy - Street-level bureaucrats · Single-factor trigger . LGBTQ · Transgender

Electronic supplementary material The online version of this article (https://doi.org/10.1007/s42972-02000010-1) contains supplementary material, which is available to authorized users.

Amy Hillier

ahillier@upenn.edu

Extended author information available on the last page of the article 
In the absence of a federal policy or Supreme Court decision delineating how Title IX protects the gender identity of students, hundreds of local school districts across the USA are developing their own policies outlining the rights of transgender and gender nonconforming (trans/GNC) students (Lewis et al. 2018). States that offer protection on the basis of gender identity do so through general anti-discrimination laws, policies explicitly protecting gender identity within K-12 schools, and written guidance from state departments of education describing how schools should support a student's gender identity. As of 2020, twenty-one states and the District of Columbia have anti-discrimination laws protecting people on the basis of gender identity (Movement Advancement Project 2020), while fifteen states and the District of Columbia have laws protecting the gender identity of students in K-12 schools (Hasenbush et al. 2018) (See Table 1). Several additional states offer guidance through their Departments of Education on effectively supporting transgender students, essentially asking for voluntary compliance with the basic tenets of model policies (Hasenbush et al. 2018; Kralik 2017). Pennsylvania has no laws prohibiting discrimination on the basis of gender identity or sexual orientation, nor has Pennsylvania's Department of Education issued guidance on supporting transgender students.

Table 1 States with laws protecting gender identity

\begin{tabular}{lll}
\hline State & $\begin{array}{l}\text { Anti-discrimination } \\
\text { law protects gender identity }\end{array}$ & $\begin{array}{l}\text { Law protecting gender } \\
\text { identity in K-12 schools }\end{array}$ \\
\hline California & $\mathrm{X}$ & $\mathrm{X}$ \\
Colorado & $\mathrm{X}$ & $\mathrm{X}$ \\
Connecticut & $\mathrm{X}$ & $\mathrm{X}$ \\
Delaware & $\mathrm{X}$ & \\
District of Columbia & $\mathrm{X}$ & $\mathrm{X}$ \\
Hawaii & $\mathrm{X}$ & \\
Illinois & $\mathrm{X}$ & $\mathrm{X}$ \\
Iowa & $\mathrm{X}$ & $\mathrm{X}$ \\
Maine & $\mathrm{X}$ & $\mathrm{X}$ \\
Maryland & $\mathrm{X}$ & \\
Massachusetts & $\mathrm{X}$ & $\mathrm{X}$ \\
Minnesota & $\mathrm{X}$ & $\mathrm{X}$ \\
Nevada & $\mathrm{X}$ & $\mathrm{X}$ \\
New Hampshire & $\mathrm{X}$ & $\mathrm{X}$ \\
New Jersey & $\mathrm{X}$ & $\mathrm{X}$ \\
New York & $\mathrm{X}$ & $\mathrm{X}$ \\
Oregon & $\mathrm{X}$ & $\mathrm{X}$ \\
Rhode Island & $\mathrm{X}$ & $\mathrm{X}$ \\
Vermont & $\mathrm{X}$ & $\mathrm{X}$ \\
Virginia & $\mathrm{X}$ & \\
Washington & & \\
\hline & &
\end{tabular}


Some states take an opposite stance by introducing laws and ballots limiting the rights of trans/GNC people. Thirteen states introduced anti-trans state laws or ballot initiatives, and fourteen states have considered legislation curtailing trans/GNC students' rights at school (Kralik 2017). Six states proposed legislation overriding local laws protecting transgender rights, but only North Carolina passed such a law until the legislature repealed the controversial HB 2 in the face of economic pressures (Hasenbush et al. 2018). At the local level, a limited number of individual school districts are establishing policies restricting the rights of transgender students. Federal circuit court rulings in Wisconsin, Pennsylvania, Virginia, and Ohio dictate that these policies violate Title IX and the Equal Protection Clause of the US Constitution.

Similar disparate policy approaches and programmatic barriers for trans/GNC people exist in social welfare, human service delivery, and social work practice. Regardless of one's commitment to upholding how the social work code of ethics protects trans/ GNC people (Dodd 2020; Woodford et al. 2013), social workers funded by state, federal, or city funds operate at the nexus of competing stakeholders and overlapping auspices that rarely reflect the needs of this population (Kattari et al. 2016; Shelton 2015). In child welfare, case managers report feeling forced to assign youth placements inconsistent with their gender identity (Identifying Author; Mallon 2009; Mallon and Hess 2014), simultaneously placing the well-being of youth at risk while forcing workers to interpret and implement competing sets of ethical, legal, and funding demands at the expense of trans/GNC young people. Case managers working in housing policy sub-systems face similar issues when the built environment and sexsegregated programmatic structures erase rather than support trans/GNC youth (Shelton 2015).

Whether it is at the state, local, or agency level, these conflicting policy approaches create implementation gray spaces where the rights afforded trans/GNC youth are unclear, contested, and managed by "street-level bureaucrats" (SLBs hereafter) who serve as front-line workers in welfare agencies, lower courts, schools, and other agencies (Lipsky 1980, p.1). Policy implementation involves "translating the goals and objectives of a policy into action" (Khan and Khandaker 2016, p.538) and occurs after a piece of legislation is altered or passed, and if it sharply departs from prior policy eras, it can result in legislative gaps or gray spaces between what the intended policy states and what occurs in reality. Since the job responsibilities of SLBs require operationalizing policy and bureaucratic structures on an individual level, they are often the first people interpreting and applying social policy in real time (Lipsky 1980; Soss et al. 2011; Tummers et al. 2015). While this can create tension between clients and workers, introduce bias into practice, and generate structural imbalances (Hasenfeld 2000; Keiser 2010), it can also create space for SLBs to engage in "small acts of resistance and refusal" in partnership with the populations they serve (Gray et al. 2015,374 ), making it an ideal location for studying how new equity-based policy is or is not championed by those tasked with carrying it out. Nonetheless, as policy implementation regarding trans/GNC youth unfolds, it is unclear how these legislative gray spaces introduce new complexities or ethical dilemmas for SLBs situated underneath competing auspices and government bureaucracies. Since policy implementation reflects uneven processes on unpredictable timelines (Bardach 2019; Kingdon 2011; Sabatier and Mazmanian 1979), the pace of these legislative shifts leaves unanswered questions surrounding the decision-making of local actors tasked with enforcing new 
statutes that may not reflect the organizational competence and institutional cooperation necessary for successful policy implementation (Iversen 2000; Weimar and Vining 1992).

This paper begins addressing these implementation gaps and questions by using the Philadelphia School District's 2016 policy (policy 252 hereafter) as a case study of how SLBs make sense of legislation aimed at protecting the well-being of trans/GNC students. Given the rapid, novel, and complex pace of expanding legislative rights for trans/GNC youth in the USA, we use a single policy case study approach that permits us to "focus on a case and retain a holistic and real-world perspective" (Yin 2014, p.5). The paper proceeds in two parts. In step with a case study approach, as well as social policy implementation analysis (Iversen 2000), part one is focused on the context, policy logic, and implementation process surrounding policy 252. Akin to an evaluation logic model or the proverbial "black box" of practice in a process evaluation (Royse et al. 2010), policy logic references how a piece of legislation ought to work and reflects assumptions about what lawmakers believe will ameliorate a given social problem. In short, it highlights how and why decisions are made about a group or a social problem. Part two focuses on the experiences of the SLBs who practice at the nexus of the competing auspices and bureaucratic structures noted prior.

\section{Part I}

\section{Background}

\section{Transgender and Gender Nonconforming Youth}

Gender identity references an innate sense of one's own gender identity, whether male, female, a combination, or neither (APA 2015; Bay-Cheng 2013). When gender identity remains consistent with the sex assigned a person at birth, they are considered cisgender (APA 2015). When gender identity differs from sex assigned at birth, they may be considered transgender, gender nonconforming, nonbinary, gender fluid, gender expansive, agender, or genderqueer (Dodd 2020; APA 2015). Children typically begin having a sense of their gender identity by age four (Diamond et al. 2011). Choosing a new name, pronouns, and clothing consistent with one's gender identity are often the first steps in a gender transition that may or may not later include medical intervention such as puberty blockers, hormone replacement therapy, and surgical procedures (Maier and Labuski 2013).

Some trans/GNC youth experience psychological distress - gender dysphoria associated with the discrepancy between their gender identity and sex assigned at birth (APA 2015). Trans/GNC youth also frequently report experiences with bullying, harassment, and discrimination in school and social service settings based on their gender identity (Mallon 2009; Mallon and Hess 2014; Shelton 2015; Stotzer et al. 2013). In schools, whether or not trans/GNC students report gender-based bullying is frequently driven by the degree to which youth feel a climate is safe and filled with staff who will meaningfully intervene (Meyer 2007, 2008). Meanwhile, teachers' responses to these youth, or lack thereof, are driven by the degree to which (1) they feel their administration will support them when they intervene in the bullying and verbal 
harassment experienced by trans/GNC and (2) the high workload demands and stressors faced by teachers, in general (Meyer 2008). Trans/GNC students who experience victimization have lower GPAs, lower self-esteem, and higher levels of depression and are less likely to have plans to pursue postsecondary education than their cisgender peers (Kosciw et al. 2015). Other research links LGBTQ victimization in educational settings with higher rates of suicidal ideation among males (Ybarra et al. 2015).

\section{Local Context}

Following several years of advocacy efforts across a range of local stakeholders and in response to the lack of protective legislation for this population at the state and federal level, a team of staff, advocates, and youth from a community-based agency proposed a policy in 2016 for the School District of Philadelphia (SDP) enumerating the rights of trans/GNC students. Anchored by a critical participatory action research (CPAR) approach that centers community voice in the policy-making process (Nightingale et al. 2016), current and former trans/GNC and LGB Philadelphia students drafted the policy based on what they felt a district should know about protecting their needs, rights, and well-being. Given the research gaps (Kattari et al. 2017; Identifying Author; Shelton 2015) and legislative invisibility (Page, 2017) experienced by this population, an approach that 'shifts the gaze from 'what's wrong with this person?' to 'what are the policies, institutions, and social arrangements that help to form and deform, enrich and limit, human development?'”(Torre et al. 2012, p. 21) was ideally suited for this policymaking process ${ }^{1}$.

The School Reform Commission $(\mathrm{SRC})^{2}$ passed the policy unanimously in June 2016 just weeks after the Obama Justice Department issued its "Dear Colleague" letter directing schools that receive public funding to allow trans/GNC students to use restrooms consistent with their gender identity (Nightingale et al. 2016). The team built on the model district policy promoted by the Gay, Lesbian, and Straight Education Network (GLSEN) that begins with an assumption that all students should feel safe and included in educational settings regardless of gender identity (GLSEN 2018). Policy 252 mandates that (1) staff use the chosen name and pronoun for all students, (2) students have the right to keep their gender identity private, (3) students are permitted to use restrooms and locker rooms consistent with their gender identity, (4) every student has the right to ask for more privacy in the context of restrooms and locker rooms, (5) the dress code must be gender neutral, (6) schools should eliminate gendersegregated activities unless they have a clear and sound pedagogical purpose, and (7) all school district personnel be trained regarding the policy (SDP 2016) ${ }^{3}$.

\footnotetext{
${ }^{1}$ The methodological process of conducting a critical participatory action research project for policy 252 in conjunction with youth and community stakeholders is the subject of another manuscript (Identifying Author).

2 The SRC was formed in 2001 and included three appointments by the governor's office and two by the mayor's office. This put SDP in state control for over 15 years until 2017 when the SRC announced that it would disband itself after a 2015 referendum where $75 \%$ of voters agreed with returning to local control under a traditional school board model (Mezzacappa and Wolfman-Arent 2017).

${ }^{3}$ While all seven components ought to function in concert, like most new legislation (Iversen 2000), it is highly likely that individual mandates will be adopted and implemented on uneven timelines based on structural support and competence. This research was conducted at onset of legislative approval. On-going research by this team is focused on longitudinal policy rollout per component.
} 


\section{Intersectional Policy Logic}

Most existing legislation on trans/GNC youth and institutional access, including those aiming to affirm and protect their rights, rest in their policy logic on "single-factor triggers" (Corus et al. 2016, p.1) like the presence, existence, or requests of a trans/ GNC young person without addressing structural context. This paper focuses on LGBT policy, but single-factor triggers are an enduring feature of social and economic policy in the USA that prevent vulnerable populations from accessing assistance. A singlefactor policy trigger means that only one qualifying characteristic or aspect of someone's identity, like race, parenting, or tax filing status, will permit access to the benefits or protections offered by a piece of legislation, thereby focusing on individual markers at the expense of other aspects of identity that overlap within institutional systems to create disparate outcomes. For example, one aim of the 2020 CARES Act was to stabilize the financial fragility of households in response to COVID-19 by providing adults with a one-time cash transfer of $\$ 1200$ and an additional $\$ 500$ for their children (US Department of Treasury 2020). The implementation mechanism rested on the single-factor trigger of filing taxes in either 2018 or 2019, which meant that if a household made too little to file for taxes, which classifies them as being in deep poverty, making it much more challenging or impossible to get the money. In this instance, the single-factor trigger of filing for taxes locked out entire populations of vulnerable households because it was not focused on the broader structural context of the experience of economic vulnerability.

The presence of single-lens or single-factor triggers in policy design often generate legislative invisibility and poor policy outcomes by reducing the lived experience and mutually constituted axes of disadvantage to one identity or social problem. In this case, trans-affirming legislation typically rests on the categorical existence of someone identifying as trans/GNC. Their very presence in educational settings triggers restroom or locker room access, thereby unintentionally placing the policy logic and accountability onus on someone publicly disclosing their gender identity. Although this approach aims at placing the needs of trans/GNC youth at the center, it erases the reality of lived experience by ignoring the ways in which advantage and disadvantage can accumulate for all youth in any educational setting.

In contrast, an intersectional approach to policy design and implementation accounts for the multiplicity of factors that amplify and reinforce vulnerability by expanding policy logic triggers beyond a single lens or identity marker to the structural context itself. Contrary to single-factor LGBTQ legislation, 252's policy logic reflects an intersectional "satisficing solution" (Simon 1972, p.167) to the limitations of the built environment and current practice limitations of competing stakeholders by decoupling restroom access from gender while asserting it at the same time. On the one hand, the legislation mandates that students have the right to access the restrooms and locker rooms corresponding with their gender identity. On the other, the policy logic disentangles the built environment from gender and attaches it to individual privacy and agency stating, "any student who has a need or desire for increased privacy, regardless of the underlying reason, should be provided access to a single stall restroom, but no student shall be required to use such a restroom" (School District of Philadelphia 2016, 4). In this way, the single-factor existence of trans/GNC youth is not the policy trigger embedded in the logic of policy 252 and other policies mirroring GLSEN's 
recommendations; it is the complex lived experience of all youth desiring safety, privacy, and well-being in educational settings.

Unlike single-lens legislation, which either reaffirms the gender binary by forcing students to use spaces in accordance with their sex assigned at birth or protects only trans/GNC students by asserting their right to a particular space, policy 252 represents an intersectional legislative approach by placing the needs of all students at the center with an anchor of privacy and agency rather than identity. Given the contentious public and federal discourse around protecting the rights of trans/GNC people (Lewis et al. 2018), this policy logic presumes that if a student or parent were to challenge policy 252 for any reason, that student has the same right to privacy as anyone else in the community "regardless of the underlying reason" (School District of Philadelphia 2016 , p. 4). In other words, rather than an individualistic approach that singles out trans/GNC students by delegating them to separate spaces like a nurse's office, a student potentially opposed to policy 252 can choose to use a separate space underneath this guideline, thereby keeping trans/GNC with their peers instead of reducing them to a single-lens policy trigger.

\section{Implementation Timelines}

While policy windows open and close on abbreviated timelines (Kingdon 2011), program implementation and institutional coordination take considerably more time, particularly if the policy represents a new approach toward a social issue (Iversen 2000). This leaves SLBs tasked with interpreting and applying policy with considerable latitude in deciding the shape implementation takes, particularly in the context of shifting policy sentiment and national mood. Sentiment and mood can reflect either a change in public opinion about a politically fraught topic or the perception that change is on the horizon, creating windows of opportunity for policy implementation (Kingdon 2011; Durr 1993). However, while actors in and around all levels of government may consider themselves adept at discerning mood (Kingdon 2011), new pieces of legislation still require operationalization by SLBs on the ground and in the community. Therefore, understanding the sentiment barriers preventing successful policy implementation also requires one to pay attention to how SLBs are situated within a politically complex environment with rapidly changing public moods and opinions.

As a nascent body of legislation, policy 252 and other policies pertaining to trans/ GNC youth arguably matter more in the hands of SLBs temporally employing their understanding of the policy's logic while programming develops on protracted timelines. However, given that SLBs, like social workers and teachers, experience a constrained sense of agency across a multiplicity of other practice domains (Donaldson and Woulfin 2018; Fairbanks et al. 2010), the degree to which they embody agency will shape their application of an institutional policy. In part two of this paper, we aim at surfacing the hidden impediments, necessary personnel competence, and sentiment barriers to sustaining a bottom-up policy designed for addressing the needs of trans/GNC youth. We intend to inform other bottom-up policy efforts and SLBs serving this population while working underneath competing auspices by drawing on data from a survey distributed to teachers and other staff immediately following a district-wide training on policy 252 to ask the following questions: (1) "How do street-level bureaucrats interpret local legislation on transgender and gender 
nonconforming youth?" and (2) "What implementation barriers do their reactions surface?".

\section{Part II}

\section{Research Methods}

\section{Recruitment and Sample}

The school district mandated training for all 9000 teachers on policy 252 as part of a half-day professional development during the fall of 2016. All K-8 teachers received training in September; all high school teachers received training in November. Principals were not required to attend but many chose to do so. School district staff affiliated with student rights and responsibilities led the half-day professional development, presenting slides and leading discussion about policies on bullying and harassment and child abuse and providing an overview of policy 252. Staff from the communitybased agency and volunteers with professional experience working with LGBTQ youth who they recruited and trained led a 1-h "gender 101" presentation-terminology, pronoun use, how gender is distinct from sexual orientation, gender transitions, and best practices with working with trans/GNC youth. The training lasted approximately $3 \mathrm{~h}$ and took place in school auditoriums across the city, with approximately 150-175 teachers and front-line staff at each site.

Full-time staff who participated in the entire policy 252 training were recruited to complete an online survey post-training through flier distribution at the conclusion of the training. The surveys contained qualitative open-ended questions, close-ended responses, and Likert scale questions. The data source for this case study relies on the qualitative responses. Staff were asked to describe their professional role, type of school, length of time they worked for the school district, race/ethnicity, age (range), and whether they are identified as LGBTQ. The remaining questions asked about knowledge and understanding of policy 252, their level of comfort with the policy, and any concerns they had about the policy or implementation. See Appendix A for the survey questions.

Of the 281 survey respondents, $88 \%$ were identified as teachers and the remainder included administrators, social workers, guidance counselors, teaching assistants, food service workers, librarians, and climate staff. Respondents were fairly evenly split by grade level: $33.4 \%$ worked at elementary schools, $29.7 \%$ in K-8 schools, $8.2 \%$ in middle schools, and $28.6 \%$ in high schools. The majority $(69.8 \%)$ had worked for the district more than 5 years, with $20.1 \%$ having worked less than 2 years and $30.8 \%$ having worked more than 15 years. The majority of participants $(71.7 \%)$ were identified as White Non-Hispanic, $17.3 \%$ identified as Black/African American, $4.0 \%$ a Hispanic, and $5.5 \%$ as biracial or some race/ethnicity not listed. The majority was identified as female $(70.7 \%)$; just one participant was identified as nonbinary. $8.6 \%$ of participants were identified as LGBTQ. The racial/ethnic demographics are largely consistent with the overall teacher population which is $67 \%$ white, $25 \%$ Black/African American, and $74 \%$ female (School District of Philadelphia 2019). 


\section{Data Procedures and Analysis}

The authors employed Braun and Clarke's (2006) thematic analysis phases to analyze all of the open-ended responses on a semantic level. Step one included all authors repetitively reading the responses in a recursive fashion. Memo-writing followed each interaction with the data and informed later stages of analysis including codebook development and theme generation. During phase one, memo-writing focused on initial impressions (Strauss 1987) while asking the following questions: "What is happening in the data?", "What events, fears, possibilities, or emotions are staff describing?", and "What reactions am I having to the data?". Memo-writing occurred independently followed by four rounds of meetings where the authors and a research assistant compared initial impressions.

In phase two, the early memos were used to develop an initial codebook containing descriptive codes capturing the basic substance of semantic responses (Saldaña 2009; Wolcott 1994). After one round of descriptive coding in Dedoose, the team met again to assess which code typologies remained missing in light of memo-writing from phases one and two. The authors subsequently added emotion codes (Saldaña 2009) capturing affective reactions in the data and value codes (Wolcott 1999), which surface the architecture of respondents underlying beliefs and attitudes as SLBs tasked with implementing policy 252. After a final round of coding, the team met two additional times to review, define, and name themes while recursively reflecting on memos generated at each stage of the process.

All research methodology was approved by the authors' Institutional Review Board, and all materials for the district-wide training were reviewed by the Director of Rights and Responsibilities for the school district. The Chief of Evaluation, Research, and Accountability for the school district reviewed the survey instrument.

\section{Results}

Findings indicate that the reactions of district staff to policy 252's implementation revolved around familial beliefs and practice habits; internalization of bureaucracy; an ambivalent relationship with mediating between personal, parental, and student agency; and sentiment barriers tied to one's own beliefs about the perception of competing rights. In keeping with the first part of the paper, we also interpret these findings in the context of the protracted and uneven nature of policy implementation.

\section{Familial Beliefs and Practice Habits}

Variations on the aforementioned themes were present among those expressing support for trans/GNC students as well as those opposed to protecting them based on the perceived cultural beliefs of families. "We are (sic) diverse school with a lot of students coming from many different countries" or the religious beliefs of families, "we have students with STRONG religious beliefs. They cannot be in a bathroom with a person of the opposite sex, let alone a transgender student. We have to be mindful of their needs too!"

The dynamic interplay between one's personal beliefs and the time staff felt it takes to alter one's habits on managing gender identity also guided how SLBs react to the 
legislation, particularly when shifting habits felt difficult. For example, staff members frequently shared how their beliefs interacted with time, sharing sentiments such as 'you can't just tell people to change their boys' and girls' lines and pronouns and expect it to happen overnight. I'm educated, open, and knowledgeable and I still haven't done it. It will take time." Other staff extended this barrier to verbal interactions with youth saying, "if you have been calling someone one name or pronoun it does not come automatic to change quickly." Still others moved beyond habits and ways of speaking and articulated that their fundamental understanding of gender is shifting in reaction to the policy. "The policy itself doesn't make me uncomfortable but it is a paradigm shift for me. For most of my life, I have thought of gender in terms of male and female." In other words, how these staff members made sense of and operationalize policy 252 is a byproduct of normative, protracted implementation timelines (Iversen 2000; Kingdon 2011) interacting with personal beliefs, the struggle to alter habits, and a situated sense of self within a large bureaucracy, which carries the potential for disciplinary action.

\section{Internalized Bureaucracy}

Rather than debating policy merits from a moral or ethical standpoint, participants who operated from a place of internalizing district guidelines focused on the mechanics of policy implementation and the risk of 440 sanctions. The " 440 " moniker commonly used across the district references the street address of administrative headquarters and is both functionally and metaphorically the space producing rules, policies, and trainings shaping the lives of staff throughout the district. Trainings led by 440 generally flow out of policy and curriculum shifts well removed from those tasked with their granular operationalization and enforcement. As such, policy 252 was perceived by some as an almost neutral bureaucratic box to check alongside every other educational mandate delivered from the larger organization.

Staff members operating from an internal sense of policies and procedures gravitated toward seeking logic hooks and checklists in the proverbial black box of programming and express frustration if they anticipated the need for a momentary judgment call. Many felt that if the procedures could "only be clear," then staff would know their role within the system, thus permitting smooth implementation. One teacher put it this way: "There's nothing special about this policy or the needs of trans students. We can learn and follow the rules and then everything will be fine." Others, on the other hand, requested there be "a prioritized checklist," a "list understanding what needs to be reported," a "clear form to fill out," "steps on what we have to do if something is wrong and when," "please tell me the politically correct terminology to use and it will be fine," and "give us clear, explicit steps. First you try A, then B, did you do C?" In other words, to these respondents, clear procedures negate moral ambiguity, ethical quandaries, familial conflict, structural inequalities, and the potential for disciplinary action by 440 .

Legal variations on this theme were also present, which staff problematized in light of their relationships with students and a desire for their safety. For example, as one teacher stated, "it's frustrating because you have to walk on egg shells around students because they 'might' identify with another orientation. However, you may not know this and this can get you, as a teacher, into some serious trouble because you didn't 
address the child correctly." Another feared, "what if you say the wrong thing or don't say the right thing and then a student kills themselves?" Rather than placing student needs at the center, many articulated fear of legal sanction saying, "let me know the laws so I can cover myself and the school district," or "the trainer mentioned us all getting sued and losing our jobs if we don't comply-NOT motivating," and another said they felt staff should be "watching your tongue to avoid a lawsuit."

\section{Agency}

A near preoccupation with the limits or possibilities associated with a sense of agency for oneself, parents, and students permeated the majority of responses. Staff reported feeling trapped between their own current or immediate sense of freedom to act within a large system that may or may not support them in the face of "parental kickback," and the long-term sense of self and, by extension, rights afforded parents and students. For example, one staff member echoed others when saying, "I feel uncomfortable asking a student what pronoun they wish to be called and how to handle parents that do not accept their transgender child."

Some responses reflected fear of differential responses between the district and those who may hold other beliefs, "I'm concerned with how this policy will be received by the families of students with extremely conservative views," while others feared conflict within parental dyads, "couldn't get to addressing what happens when the student is headed in one direction and the parents - or one of them - is NOT supportive of their child's gender identity. Where is the school supposed to be?" Here, too, legal concerns surfaced regarding parents. "We need to have clarity on the legal ramifications of name changes and discussions around liability of changing things without parental consent." The aforementioned staff concerns repeatedly surfaced alongside other fears that they were being tasked with implementing policies absent the full support of 440 or their principals, sharing statements such as "nothing makes me uncomfortable, but I'm nervous that my administration would not help me support students if I needed to" or "if we do it wrong is there a civil rights violation?"

A long-term sense of agency or self-determination represents a more fixed sense of oneself over time extending independent of and beyond current actions, whereas as a current or immersed sense of self-determination is making sense of being a momentary agent of action (Marcel 2003). These entwined, but distinct, notions of selfdetermination were playing out in the gray areas generated by introducing legislation fundamentally overturning how institutions construct ways of being previously limited to binary understandings of gender. This could prompt uncertainty even when staff members expressed a desire to support trans/GNC youth. Consider this staff member who shared, "honestly, I'm more concerned about the student who is struggling with their gender identity and the 'accommodations' and 'procedures' put in place to help them may wind up hurting them," or another who said, "I don't even know where to begin with asking for help. I want my kids feeling included and that is something I want more help with."

In this context, SLBs were placed in a dissonant position between the current notion of agency they afford themselves as people tasked with interpreting 252, and the longterm sense of agency and rights afforded parents and students whose lives and selfdetermination extend well beyond the boundaries of immediate bureaucracy governing 
the lives of front-line staff. The ambivalence present in this space was also mediated by one's own personal values and beliefs about trans/GNC youth and the degree to which staff may reflect notions of the internalized bureaucracy noted prior. Either way, the conflict between competing notions of rights, the needs of youth, and ambient anxiety about one's place within the larger system echoed throughout the staff reflecting the structural climate shaping how people react to gender nonconforming youth.

\section{Sentiment Barriers}

Whether for or against protecting the rights of trans/GNC youth, a complex interplay between one's personal beliefs about gender, the uneven nature of new legislation, and the limits of agency in a larger bureaucracy generated considerable confusion. Although policy 252 was a local piece of legislation designed by and for trans/GNC youth, the sentiments staff members articulated provided some insight into how any front-line SLB tasked with implementing new legislation regarding gender identity may react. Social service delivery, educational systems, and the built environment operate on the assumption of a gender binary that remains difficult to shift. Thus, those working to implement policies protecting the rights of this population were forced to navigate their own beliefs about gender in a larger structure and space fundamentally lacking any recognition of gender outside the binary. Beyond an expected continuum that both valorizes and demonizes policy 252, the most salient sentiment barrier present in this sample was a perception that equitably protecting the rights of everyone remains impossible. Consider again the staff members echoing statements such as "we are (a) diverse school with a lot of students coming from many different countries with different religious.... Some might have to hold their bathroom use during the school day because of their religious beliefs." False assumptions that misperceive policy 252 as yet another single-factor trigger piece of legislation permeated responses like this. Even though the policy logic designed by the youth situates agency and privacy rather than identity as the legislative trigger, staff still reacted as though policy 252 represents a zero-sum game with clear winners and losers. This indicated that perhaps the most crucial sentiment barrier toward achieving equity in this policy sub-system was the presumed path dependency that satisficing solutions linger out of reach.

\section{Limitations}

Three key limitations surround this research. First, the data presented here are drawn from a relatively small convenience sample of those who chose to complete the survey after the mandatory professional development. Survey participation was not compulsory. While we know that the racial/ethnic and gender distribution of survey participants was similar to the overall teacher population, we have no way of knowing how attitudes within the convenience sample compare with those of all teachers. It is likely that teachers with strong opinions - critical and supportive of policy 252-were more likely to complete the survey. Second, the context of the city of Philadelphia and the particular state of Philadelphia's school district undoubtedly inform some of the responses, but it is not possible to specifically identify how that might impact generalizability of findings to other school districts. As McWilliams (2016) notes, Philadelphia school district staff are structurally situated in between neoliberal educational 
approaches while operating in dilapidated buildings, resource-poor environments, and overcrowded conditions. Therefore, introducing any new piece of legislation carries the potential for resistance because it can be interpreted as yet another task for SLBs to manage in austerity-driven conditions. Nonetheless, given an extensive body of literature documenting austerity-driven strains experienced by teachers and staff in lowincome urban educational settings (Cucchiara 2013; McWilliams 2016; Ravitch 2013), it is likely that SLBs in similar cities have far more in common with this group of respondents than not. Finally, this research does not benefit from the counterweight of data collected with members of the administration including principals or 440 staff. Provided one could obtain access, future research in this area would benefit from comparing the experiences of administrators with that of teachers. Future research would also benefit from following implementation arcs over time and across different geographic regions.

\section{Discussion}

Even though policy 252 represents a piece of legislation where trans/GNC voices were centered in the policy-making process, the responses of SLBs still reflect implementation barriers well-known in the policy literature. Centering the LGBTQ community in a bottom-up policy process arguably creates a more equitable and satisficing solution in the absence of federal and state action, but equitable policy approaches are not synonymous with bypassing the difficulties associated with operationalizing new legislation on a politically contested topic. Fear of sanctions, an internalized sense of bureaucracy, and one's own level of support for trans/GNC youth continue interacting in the uneven application of policy and protective legislation for this population.

In the absence of clear federal or consistent state legislation protecting the rights of trans/GNC students, school districts across the country will continue to develop their own policies. Educating school staff about best practices around gender identity is only part of the challenge. Implementation of these policies will rely on school administrators, teachers, and other staff and must take into consideration the larger power dynamics and constraints on agency that characterize these bureaucracies. The way these frontline workers - "street-level bureaucrats"-interpret and implement these policies will determine the extent that trans/GNC students are fully included in all aspects of public education.

As reflected in staff responses above, SLBs are legitimately caught in a legal gray space if parents disagree with local policies regarding trans/GNC youth. Without a federal law that explicitly protects the rights of this population, the closest legal protection known to these authors is situated within the fourteenth amendment's equal protection clause which protects people from discrimination due to their minority status, which can include sexual orientation (Bohm et al. 2016). However, the equal protection clause is limited in its application and thus far court rulings that pertain to trans/GNC youth and school districts only address discrimination faced by students in their schools if youth can demonstrate they experienced discrimination "based on a district policy or a long-standing custom" (Bohm et al. 2016, p. 130). To date, the courts have not resolved how these situations may apply to parents. In other words, until the rights of all LGBT youth are protected at the federal level, SLBs will need to navigate local laws and institutional policies. While daunting, this is not an impossible 
task and is one well-suited to the social work profession and art of practice which has always operated at the nexus of competing auspices. Like teachers, social workers are situated in between the failures of the market, the failures of the state, and the failures of policy (Abromowitz and Zelnick 2018). As such, the field contains a rich history of practice experience in mediating between competing tensions through using the social work code of ethics. In this case, SLBs can look to other areas of social work practice with similar tensions such as caseworkers who have to decide whether or not to place a minor trans/GNC client in placements inconsistent with their gender identity (Mallon 2009; Mallon and Hess 2014). In these uncertain instances, some social workers default to the commitment for advancing human rights within the social work code of ethics for guidance which calls on them to create inclusive learning and practice environments (Wagaman et al. 2018).

While we focused here on a local, legislative approach toward full inclusion of the LGBTQ community, this case study also illustrates some of the implementation barriers stakeholders can expect to encounter with SLBs while trying to influence higher orders of government through local advocacy and action. Indeed, the ambivalence and agentic struggle present in the responses prior belie the true nature of how difficult altering the discourse on gender fluidity remains, particularly given the fraught political environment surrounding LGBTQ rights.

Acknowledgments We are grateful to Siobhan Costanzo, Ben Libertore, and Hillary Nguyen for their contributions to the qualitative coding and conceptualization of this research.

Funding Information Funding was provided by the School of Social Policy \& Practice and the Fels Policy Research Initiative at the University of Pennsylvania.

\section{Compliance with Ethical Standards}

Conflict of Interest The authors declare that they have no conflict of interest.

\section{References}

Abromowitz, M., \& Zelnick, J. (2018). The logic of the market versus the logic of social work: Whither the welfare state? Social Work \& Society, 16(2).

American Psychological Association. (2015). Guidelines for psychological practice with transgender and gender nonconforming people. American Psychologist, 70, 832-864.

Bardach, E. S. (2019). Practical guide for policy analysis: The eightfold path to MoreEffective problem solving. Los Angeles, CA: Sage Publications.

Bay-Cheng, L. (2013). Human sexuality. In C. Franklin (Ed.), Encyclopedia of social work. Washington, D.C.: Oxford University Press.

Bohm, A. L., Del Duca, S., Elliott, E., Holako, S., \& Tanner, A. (2016). Challenges facing. LGBT Youth. Georgetown Journal of Gender \& Law, 17(125), 127-151.

Braun, V., \& Clarke, V. (2006). Using thematic analysis in psychology. Qualitative Research in Psychology, 3, 77-101.

Corus, C., Saatcioglu, B., Kaufman-Scarborough, C., Blocker, C. P., Upadhyaya, S., \& Samuelson, A. (2016). Transforming poverty-related policy with intersectionality. Journal of Public Policy \& Marketing, 35(2), 211-222.

Cucchiara, M. B. (2013). Marketing schools, marketing cities: Who wins and who loses when schools become urban amenities. Chicago, IL: University of Chicago Press. 
Diamond, L., Pardo, S. T., \& Butterworth, M. R. (2011). Transgender experience and identity. In Handbook of Identity Theory and Research. New York, NY: Springer Publishing.

Dodd, S. J. (2020). Sex positive social work. New York: Columbia University Press.

Donaldson, M. L., \& Woulfin, S. (2018). From tinkering to going "rogue": How principals use agency when enacting new teacher evaluation systems. Educational Evaluation and Policy Analysis, 40(4), 531-556.

Durr, R. H. (1993). What moves policy sentiment? The American Political Science Review, 87(1), 158-170.

Fairbanks, C., Duffy, G. G., Faircloth, B., He, Y., Levin, B. B., Rohr, J., \& Stein, C. (2010). Beyond knowledge: Exploring why some teachers are more thoughtfully adaptive than others. Journal of Teacher Education, 61, 161-171.

GLSEN. (2018). Model school district policy on transgender and gender nonconforming students. https://www.glsen.org/activity/model-district-policy-transgender-and-gender-nonconforming-students. Accessed 13 January 2020.

Gray, M., Dean, M., Agllias, K., Howard, A., \& Schubert, L. (2015). Perspectives on neoliberalism for human service professionals. Social Service Review, 89(2), 368-392.

Hasenbush, A., Flores, A. R., \& Herman, J. L. (2018). Gender identity nondiscrimination Laws in public accommodations: A review of evidence regarding safety and privacy in public restrooms, locker rooms, and changing rooms. Sexuality Research and Social Policy, 16(1), 70-83.

Hasenfeld, Y. (2000). Organizational forms as moral practices: The case of welfare departments. Social Service Review, 74(3), 329-351.

Iversen, R. R. (2000). TANF policy implementation: The invisible barrier. Journal of Sociology and Social Welfare, 27(2), 139-159.

Kattari, S. K., Whitfield, D. L., Walls, E., Langenderfer-Magruder, L., \& Ramos, D. (2016). Policing gender through housing and employment discrimination: Comparison of discrimination experiences of transgender and cisgender LGBQ individuals. Journal of the Society of Social Work Research, 7(3), 427-447.

Kattari, S. K., Barman-Adhikari, A., DeChants, J., \& Rice, E. (2017). Social networks and sexual risk factor differences between cisgender heterosexual and cisgender LGBQ homeless youths. Journal of Gay \& Lesbian Social Services, 29(2), 182-200.

Keiser, L. R. (2010). Understanding street-level bureaucrats' decision making: Determining eligibility in the social security disability program. Public Administration Review, 2, 247-257.

Khan, A. R., \& Khandaker, S. (2016). Insight into policy implementation and implementation performance. Public Policy \& Administration, 15(4), 538-548 A critical.

Kingdon, J. W. (2011). Agendas, alternatives, and public policies. Boston, MA: Longman.

Kosciw, J. G., Greytak, E. A., Palmer, N. A., \& Boesen, M. J. (2015). The 2013 National School Climate Survey: The experiences of lesbian, gay, bisexual, and transgender Youth in our nation's schools. New York, NY: Gay, Lesbian, \& Straight Network.

Kralik, J. (2017). "Bathroom Bills on Trial." National Conference of State Legislatures. http://www.ncsl. org/Portals/1/Documents/magazine/articles/2017/SL_0117- BathroomBills.pdf.

Lewis, M. M., Garces, L. M., \& Frankenberg, E. (2018). A comprehensive and practical approach to policy guidance: The Office for Civil Rights' role in education during the Obama administration. Educational Researcher, 48(1), 51-60.

Lipsky, M. (1980). Street-level bureaucracy: Dilemmas of the individual in public services. New York, NY: Russel Sage Foundation.

Maier, S. C., \& Labuski, C. M. (2013). The demographics of the transgender population. In A. K. Baumle (Ed.), International handbook on the demography of sexuality. Dordrecht, Netherlands: Springer.

Mallon, G. (2009). Social work practice with transgender and gender variant Youth. New York, NY: Routledge.

Mallon, G., \& Hess, P. M. (2014). Child welfare for the twenty-first century: A handbook of practices, policies, and programs. New York, NY: Columbia University Press.

Marcel, A. J. (2003). The sense of agency: Awareness and ownership of action. In J. Roessler \& N. Eilan (Eds.), Agency and self-awareness: Issues in philosophy and psychology. Oxford, England: Clarendon Press.

McWilliams, J. (2016). Teaching amidst precarity: Philadelphia's teachers, neighborhood schools, and the public education crisis. Workplace, 26, 20-33.

Meyer, E. (2007). Bullying and harassment in secondary schools: A critical feminist analysis of the gaps, overlaps, and implications from a decade of research. American Education Research Association.

Meyer, Elizabeth. 2008. Gendered harassment in secondary schools: Understanding teachers' (non) interventions. Gender and Education, 20, 555-570. Movement Advancement Project. (2019). Equality Maps: Overall Policy Tally. http://www.lgbtmap.org/equality-maps Accessed 20 May 2019. 
Mezzacappa, D., Wolfman-Arent, A. (2017). SRC makes Philly education history, votes to dissolve. WHYY. https://whyy.org/articles/src-makes-philly-education-history-votes-dissolve/. Accessed 13 January 2020.

Movement Advancement Project. (2020). Equality Maps. https://www.lgbtmap.org/equality-maps Page, M. (2017). Forgotten youth: Homeless LGBT youth of color and the runaway and homeless youth act. Northwestern Journal of Law \& Social Policy, 12(2), 17-45.

Nightingale, D. S., Fudge, K., \& Schupmann, W. (2016). Learning agendas. Washington D.C.: Urban Institute, evidence-based policymaking collaborative. U.S. Department of Justice and U.S. Department of Education 2016.

Page, M (2017). Forgotten Youth: Homeless LGBT Youth of Color and the Runaway and Homeless Youth Act. 12 Nw. J. L. \& Soc. Pol'y. 17

Ravitch, D. (2013). Reign of error: The hoax of the privatization movement and the danger to America's public schools. New York, NY: Knopf Publishers.

Royse, D., Thyer, B. A., \& Padgett, D. K. (2010). Program evaluation: An introduction (fifth ed.). Belmont, CA: Wadsworth.

Sabatier, P., \& Mazmanian, D. (1979). The implementation of regulatory policy: A framework of analysis. Davis, Ca: Institute of Governmental Affairs.

Saldaña, J. (2009). The coding manual for qualitative researchers. Thousand Oaks, CA: Sage Publications.

School District of Philadelphia (2016). Policy 252: Transgender and Gender Non-conforming Students. https://www.philasd.org/src/wp-content/uploads/sites/80/2017/06/252.pdf. Accessed 21 January 2020.

School District of Philadelphia. (2019). District employees and finance: Teacher demographics. https://www. philasd.org/performance/programsservices/open-data/district-information/ Accessed 23 December 2019.

Shelton, J. (2015). Transgender youth homelessness: Understanding programmatic barriers through the lens of cisgenderism. Children and Youth Services Review, 59, 10-18.

Simon, H. (1972). Theories of bounded rationality. In C. B. McGuire \& R. Radnor (Eds.), Decision and organization. Amsterdam, Netherlands: North-Holland Publishing Co..

Soss, J., Fording, R. C., \& Schram, S. F. (2011). Disciplining the poor: Neoliberal paternalism and the persistent power of race. Chicago: University of Chicago Press.

Stotzer, R., Silverschanz, \& Wilson, A. (2013). Gender identity and social services: Barriers to care. Journal of Social Service Research, 39(1), 63-77.

Strauss, A. L. (1987). Qualitative analysis for social scientists. New York, NY: Cambridge University Press.

Torre, M. E., Fine, M., Stoudt, B. G., \& Fox, M. (2012). Critical participatory action research as public science. In In APA Handbook of Research Methods in Psychology, Volume 2, Research Designs: Quantitative, Qualitative, Neuropsychological, and Biological. Washington, D.C.: American Psychological Association https://home.treasury.gov/policy-issues/cares.

Tummers, L. L. G., Bekkers, V., Vink, E., \& Musheno, M. (2015). Coping during public service delivery: A conceptualization and systematic review of the literature. Journal of Public Administration Research and Theory, 25(4), 1099-1126.

U.S. Department of the Treasury. (2020). The CARES Act Works for All Americans. https://home.treasury. gov/policy-issues/cares. Accessed 28 May 2020.

Wagaman, M. A., Shelton, J., \& Carter, R. (2018). Queering the social work classroom: Strategies for increasing the inclusion of LGBTQ persons and experiences. Journal of Teaching in Social Work, 38(2), 166-182.

Weimar, D. L., \& Vining, A. R. (1992). Policy analysis: Concepts and practice. Englewood Cliffs, NJ: Prentice Hall.

Wolcott, H. F. (1994). Transforming qualitative data. Thousand Oaks, CA: Sage.

Wolcott, H. F. (1999). Ethnography: A way of seeing. New York, NY: Rowman \& Littlefield.

Woodford, M., Brennan, D. J., Gutierrez, L., \& Luke, K. (2013). U.S. graduate social work Faculty's attitudes toward lesbian, gay, bisexual, and transgender people. Journal of Social Service Research, 39(1), 50-62.

Ybarra, M. L., Mitchell, K. J., Kosciw, J. G., \& Korchmaros, J. (2015). Understanding linkages between bullying and suicidal ideation in a national sample of LGB and heterosexual youth in the United States. Prevention Science, 16(3), 451-462.

Yin, R. K. (2014). Case study research: Design and methods. Thousand Oaks, CA: Sage.

Publisher's Note Springer Nature remains neutral with regard to jurisdictionalclaims in published maps and institutional affiliations. 


\section{Affiliations}

\section{Amy Castro Baker ${ }^{1} \cdot$ Amy Hillier ${ }^{1} \cdot$ Monique Perry $^{2}$}

Amy Castro Baker

amybaker@sp2.upenn.edu

1 School of Social Policy \& Practice, University of Pennsylvania, McNeil 320, 3718 Locust Walk, Philadelphia, PA 19104, USA

2 Graduate School of Education, University of Pennsylvania, 3700 Walnut Street, Philadelphia, PA 19104, USA 